\title{
Correspondence
}

\section{Engage public in gene-editing policy}

I agree that new mutational technologies such as gene editing and gain-of-function research call for public debate, global engagement and broad evaluation by experts so that policy-makers are properly informed (see Nature $\mathbf{5 2 1}, 5$; 2015).

The degree of experimental freedom in research is not the only thing at stake, however. At issue is public trust in the institution of science itself. Similar policy challenges arose when recombinant DNA technology was first developed, which led to safety guidelines being drawn up at the 1975 US Asilomar conference.

An international set of such conferences is now needed to assess the potential risks associated with the latest DNA technologies and to develop a common understanding of where lines should be drawn (see also E. Lanphier et al. Nature 519, 410-411 (2015) and D. Baltimore et al. Science 348, 36-38 (2015)).

The original Asilomar meeting failed to engage the public in discussions, which we now know is crucial to the regulatory decision-making process. Had it done so, the resulting guidelines on recombinant DNA might have extended to legislation covering all users - including the military and commercial sectors - and not just those funded by the US National Institutes of Health. Filippa Lentzos King's College London, UK. filippa.lentzos@kcl.ac.uk

\section{Blood-transfusion decisions not simple}

We consider that your discussion on the possible overuse of blood transfusions simplifies a complex issue (Nature 520, 24-26; 2015).

Readers might infer, for example, that a standardized transfusion protocol is safer than individualized bloodmanagement care, or that restricted transfusion in response to a particular haemoglobin concentration is at least as safe and effective as transfusion titrations determined by a range of haemoglobin levels. In fact, neither hypothesis has been tested. As you indicate, physicians need to take into account individuals' primary disease as well as any complications and accompanying disorders. Such factors can improve patient care in the longer term, beyond any simple numerical guidelines for restrictive-transfusion practices.

We have shown that a restrictive-transfusion threshold at 7 grams per decilitre of haemoglobin can be problematic for people with stable blood pressure and cardiovascular status (H. G. Klein and C. Natanson Ann. Intern. Med. 157, 753-754; 2012). We argue elsewhere that the pivotal trials you cite would have been more robust had they included a range of transfusion triggers, instead of just two arbitrarily selected haemoglobin levels, and a standard-of-care control arm to incorporate all clinical and lab observations for each patient (K. J. Deans et al. Vox Sang. 99, 16-23; 2010). Restrictive practices save blood, but they do not necessarily save lives. Harvey G. Klein, Irene CortésPuch, Charles Natanson National Institutes of Health, Bethesda, Maryland, USA. hklein@dtm.cc.nih.gov

\section{Water: megacities running dry in Brazil}

São Paulo and Rio de Janeiro are running out of drinking water owing to an extended drought and disjointed water-resource planning in Brazil. To avert social, economic and political disruption, scientific information must be translated more effectively into water policy.

For example, industrial sectors need information on how to adapt hardware, methods and practices to mitigate the water shortage; state and regional governments need guidance on economic-development models that are tailored to the capacities of regional freshwater ecosystems.

Educating the public and all stakeholders in water usage is a priority, and is a primary function of Brazil's International Centre for Education, Capacity Building and Applied Research in Water (HidroEX). Political organizations must promote responsible water use, as is proving successful in California. Richard Meganck Oregon State University, Corvallis, USA.

Karl Havens University of Florida, Gainsville, USA.

Ricardo M. Pinto-Coelho Federal University of Minas Gerais, Brazil. rameganck@gmail.com

\section{Water: halt India's groundwater loss}

India is not doing enough to stop groundwater depletion (see M. Rodell et al. Nature 460, 9991002; 2009 and P. P. Mujumdar Nature 521, 151-155; 2015). This could compromise its capacity to resolve food-security issues in the face of climate change.

India's water storage per head of population is only 200 cubic metres, compared with around $2,500 \mathrm{~m}^{3}$ in China and almost $6,000 \mathrm{~m}^{3}$ in the United States. Farmers in India are digging ever deeper for water, unaware of the long-term repercussions.

Government plans for moreefficient water usage include the National Water Mission and National Water Policy. Water regulation, management and monitoring are regionally but not federally controlled, so enforcing such policy initiatives in different states is likely to take several years.

A national water project to irrigate some 35 million hectares of land through river linking and extensive canal networks could prove impractical because of its cost (US $\$ 92$ billion, or around $5 \%$ of India's 2013 gross domestic product) and because of the political complexities associated with rivers that cross other countries.

None of these plans will reduce groundwater depletion in the short term. They need to be supported with public education on water use and with integrated water-resource management. Leading local policy-makers and central administration must cooperate to meet the challenge before it is too late.

Bobban Subhadra Quorum Innovations, Sarasota, Florida, USA. bbobban@gmail.com

\section{Water: a drought plan for biodiversity}

To help combat California's worst drought for more than 1,000 years, state governor Jerry Brown has called for the replacement of urban lawns with drought-tolerant landscaping (see go.nature.com/cvqw4l). Applied on a larger scale than he proposes, this move would boost the region's threatened biodiversity and improve water conservation.

The governor's designated " 50 million square feet of lawns" amounts to 4.64 square kilometres, or just $0.04 \%$ of the estimated $11,000 \mathrm{~km}^{2}$ of turf grass in California (C. Milesi et al. Environ. Manage. 36, 426-438; 2005). Planting drought-resistant native vegetation instead of nonnative turf grasses would spare water and help to restore native ecosystems in the longer term.

Ecologists should work with municipal initiatives to expand such refurbished urban green spaces into nearby areas of native vegetation, which would restore connectivity between native-habitat remnants. This model could be applied in other drought-stricken regions with high biodiversity, such as those in Australia and southeast Brazil. Alexander C. Lees Museu Paraense Emílio Goeldi, Belém, Pará, Brazil.

Peter Bowler University of California, Irvine, USA. alexanderlees@btopenworld.com 